\title{
Advancing Outcomes Research in Managed Care Pharmacy: A Call to Action
}

\author{
Pharmacists practicing in managed care settings must become better \\ educated in pharmacoeconomics and outcomes, initiate formal research \\ in the area, document their successes as they affect the clinical outcomes \\ in the populations they manage, and support their parent companies in \\ marketing these successes for membership retention and growth.
}

$\Lambda$ $s$ managed care pharmacy has developed, the industry has used many types of controls and has required its practitioners to adjust to different measurement methods. Historically, the measures used have been cost focused. But today. purchasers and end users of the managed care product are turning the focus more toward quality measures, with a greater emphasis on comparing and contrasting physicians, health plans, programs, and processes. Consumers are demanding better performance from managed care and are

Dianne A. Kane Parker

\section{Ainhor}

DIANNE A. KANE PARKER, PHARM.D, is Regional Project Manager, Pharmacia \& Upjohn, Kalamazoo, MI.

Copyright $\odot 1998$, Academy of Managed Care Pharmacy, Inc. All rights reserved. looking for quantifiable results.

Being a successful player in the managed care market in the future will require careful expenditures and thoughtful evaluations of how the business of health care actually affects the population beneath its umbrella. The methods by which this will be defined include pharmacoeconomics and outcomes evaluations.

The pharmacist will play a key role as managed care organizations (MCOs) increase their use of formal measurements. Even in the early, rudimentary days (not all that long ago) of quality studies, the pharmacist in a managed care plan was called upon to participate in the multidisciplinary team to complete National Committee for Quality Assurance (NCQA) recommendations. The pharmacist often provided the only access to study populations, such as diabetics, via prescription claim database extraction.
For over two decades, pharmacists have been collecting data, which is now a powerful tool for the future success of health management initiatives, as well as an example for data consolidation processes. In addition, pharmacists in a variety of practice settings continue to play key roles to assure healthy outcomes since they hold positions that provide direct patient interventions, critical compliance counseling, education, and other essential services.

A review of the highlights of managed care pharmacy is depicted in Table 1. What was required for success in the marketplace 20 years ago differs dramatically from what is required now. What will be needed in the future will be an evolutionary step beyond what is required today. Increasing level of control and understanding of the dynamics of a given patient population is represented by the continuum:

Component management $\rightarrow$ case management $\rightarrow$ disease management $\rightarrow$ outcomes management

\section{BACKGROUND}

In the early years of managed care pharmacy, success was measured by achieving cost reductions through the elimination of duplicate prescriptions, assuring beneficiary match, controlling quantities dispensed, and preventing unnecessary waste. Later refinements of 
Table 1. Highlights of Managed Care Pharmacy

\begin{tabular}{|c|c|c|c|}
\hline . & Focus & Differentiated By & Elements of Success \\
\hline Unmanaged (1970s) & Administrative efficiency & $\begin{array}{l}\text { Low administrative fees } \& \text { easy } \\
\text { access }\end{array}$ & - Claim processing large network of sites \\
\hline $\begin{array}{l}\text { Managed: Phase I } \\
\text { (mid-1980s) }\end{array}$ & Unit cost management & $\begin{array}{l}\text { Deep discounts } \& \text { low } \\
\text { dispensing fees }\end{array}$ & $\begin{array}{l}\text { - Successful network contracting } \\
\text { - Successful manufacturer rebate contracting } \\
\text { - Online claim processing for speed and accuracy }\end{array}$ \\
\hline $\begin{array}{l}\text { Managed: Phase } 2 \\
\text { (late 1980s) }\end{array}$ & $\begin{array}{l}\text { Total pharmacy cost } \\
\text { management }\end{array}$ & Drug plan cost savings & $\begin{array}{l}\text { - DUE } \\
\text { - Formulary management } \\
\text { - Unit cost management } \\
\text { - Integrated pharmacy networks including mail } \\
\text { order } \\
\text { - Using clinical expertise for utilization } \\
\text { management and other intervention and } \\
\text { educational activities }\end{array}$ \\
\hline $\begin{array}{l}\text { Managed: Phase } 3 \\
\text { (late 1990s) }\end{array}$ & $\begin{array}{l}\text { Total health care cost } \\
\text { management; quality } \\
\text { measures; HEDIS com- } \\
\text { pliance }\end{array}$ & $\begin{array}{l}\text { Outcomes evaluation and } \\
\text { management }\end{array}$ & $\begin{array}{l}\text { - More cooperative activity between medical and } \\
\text { pharmacy } \\
\text { - More involvement with employer-driven } \\
\text { demands for health programs }\end{array}$ \\
\hline$\overline{\text { Beyond }}$ & Evolving & $\begin{array}{l}\text { Value measured by proven } \\
\text { outcomes }\end{array}$ & $\begin{array}{l}\text { - Outcomes management } \\
\text { - Total patient care } \\
\text { - Disease management } \\
\text { - Pharmacoeconomic studies } \\
\text { - Proactive member education } \\
\text { - Excellent system for data integration } \\
\text { - Artificial intelligence } \\
\text { - Predictive modeling } \\
\text { - Health risk assessment tools \& protocols }\end{array}$ \\
\hline
\end{tabular}

management processes included the use of mandatory generics, the application of differential copayments to provide appropriate incentives, rudimentary formularies, and retrospective drug utilization reviews (DURs). Additional measures restricted quantities of medication dispensed or eliminated medically unnecessary expenditures, such as those intended for cosmetic purposes. As managed care advances, methods for achieving the goals of cost reduction and provision of high-quality health care are becoming more complex, thus harder to conceptualize and more difficult to evaluate. The evolving system will rely increasingly on outcomes research.

A highly visible part of managed care pharmacy and a target of increasing consumer dissatisfaction is medication formularies. Though effective as a costmanagement tool, and generally founded firmly in clinical appropriateness and patient equity, formularies are becoming a symbol of what is perceived to be wrong with managed care.

Some of the criticisms levied at MCOs include assertions that they do not possess enough data to evaluate quality-of-life issues and then apply them to formulary decisions. Rather, it often is perceived that decisions are capricious or rebate-driven. As a result, there has been an abundance of media attacks and some states are writing legislation intended to protect patients who may suffer adverse events from frequent switching of agents purported to be "therapeutically interchangeable."

In late 1996 Milt Freundenheim of the New York Times ${ }^{1}$ attacked managed care formulary processes by highlighting isolated cases of adverse events and drawing attention to the discomfort felt by the members of the American Medical Association and pharmacist groups opposing these practices. In his article, Mr. Freundenheim wrote, "Medical decisions are being dictated by deals between drug makers and health plans, critics say, though little research is available on how often substituting one drug for another may cause harm. The practice also tends to favor older treatments, which compete for market share on price, over new, but expensive, ones that may have fewer side effects and be more effective."

Pharmacists will agree that, for the vast majority of patients; therapeutic 
- Continued from page 258

substitution is acceptable and adverse events occur at a lower incidence than a lay person might think. Yet, it is clear that some therapeutic switch programs are carried out in what seems to be a clandestine or haphazard manner; the patient discovers the fact only when presenting to the pharmacy and learning the bad news that now his drug is, not covered on the plan. A few bad interchange programs make all MCOs appear culpable.

Some managed care plans are introducing formulary variations to answer the concern. For example, some plans are introducing a provision for members to select nonpreferred agents, but at a higher copayment, offsetting a potential loss to the plan and alleviating the point-of-service hassle. But this is a temporary solution. Until valid outcomes evaluations or sound pharmacoeconomic processes are applied consistently to formulary decision making, the attacks, controversy, and protective legislation will continue.

\section{CHANGING PARADIGMS}

In a survey of eight pharmacy benefit managers conducted in 1996, only one was monitoring clinical effectiveness or tracking health outcomes of enrollees, and this one did so for one client only. ${ }^{2}$ In addition, no effort was made by any of the respondents to determine what, if any, actions were taken by the network pharmacists when online messages were delivered at the point of service. Without the ability to evaluate the effects of their formulary decisions, interventions, and drug-use evaluation (DUE) efforts on overall health outcomes, there is little defense that can be made for the processes now widely scrutinized by regulators, purchasers, and members:

The ability to conduct the evaluations that will result in truly useful outcomes information will require a radical change in the current paradigms of health care. Evaluation of outcomes necessitates the study of the entire continuum of health care. This is contrary to what continues to prevail in managed pharmacy practice, which is a focus on component costs. Under this paradigm, the department head for each component of the health delivery process is responsible for management of costs within his or her professional area. This creates an impossible task for pharmacists who are under pressure to drive down costs in the pharmacy budget. In most managed pharmacy settings, the managers who are responsible for the drug budget have little or no influence over benefit design or the rate of drug utilization (unless significant access barriers are in place at the point of service). In general, they cannot directly link nonpharmaceutical benefits gained, such as a reduction in bed days or an averted trip to an emergency room, to justify costs expended in the pharmacy budget. The focus on component costs also ignores the reality of the health care equilibrium: that drug use causes or is affected by hospitalizations, medical visits, and nontraumarelated emergency visits. Sometimes medical costs are not known to the plan because the risk has been delegated. Often, required information is not collected in a coordinated manner, undermining the review and evaluation necessary to obtain a complete picture of the continuum of care.

Contracting strategies have driven the segmentation of health care costs in the past. A new trend is emerging to address this problem by revising the terms of contracts to achieve greater efficiencies, track events more completely, and realize the economic value of aggressive health management programs. For example, physician practice groups are given the risk for pharmacy expenditures and hospital risk contracts are being revised to return some or all risk back to plans.

\section{EMPLOYER/PURCHASER ISSUES}

In the future, the purchasers of health care-largely employers-will be looking for more than the best price.
They are starting to evaluate managed care based on programs implemented by the health plans that provide the measurable outcomes they value, such as expending fewer overall patient care dollars and helping patients return to work, stay working longer, or miss fewer work days due to chronic illnesses. Therefore, they are looking for benefits like successful smoking cessation, weight-reduction programs, AIDS treatments that keep those affected healthier and working longer, case management and supportive rehabilitation programs that result in shorter hospitalizations, and comprehensive depression and diabetes management programs.

Corporate coalitions, such as the Pacific Business Group on Health (PBGH), are leading the charge toward demanding reform of the health care system. In an interview with the Wall Street Journal, Patricia Powers, executive director of $\mathrm{PBGH}$, agreed that there is a backlash against managed care. ${ }^{3}$ Using the example of the maternity two-day stay, she said, "There is clearly dissatisfaction among women for being discharged within 24 hours of having a baby. Is the best way to address it to legislate two-day stays or should we look at outcomes of care? If the HMO industry can't produce outcomes [data] showing that a one-day stay isn't at least as good as a two-day stay, then it deserves to be legislated." She also discussed the pharmacy benefit as a point of dissatisfaction for employees. In 1998 PBGH expects to call for some uniformity in formularies among their contracted health plans. Good outcomes data and the application of pharmacoeconomics in the decision-making process for formulary composition will be important parameters for plans to present.

Employers are an important driver for change because they decide what they will pay for and, in the process, help to redesign the product. Excellent performance will justify higher premiums for those plans demonstrating better outcomes. Health plans that can provide objective measures of their success 
in these areas not only keep employers happy but tend to produce greater patient satisfaction. Patient satisfaction is the key to member retention.

Losing members has many significant ramifications. For example, it can cost as much as five times more to recruit a member than to retain a member. The problem of disenrollment is more than financial. In an overall scheme to provide quality health care services to a defined population, the disenrollment factor affects programs meant to assure quality initiatives. Managing a population of asthmatics or diabetics becomes more difficult as members, and their outcomes results, leave the system.

\section{PATIENTS DEMAND MORE}

MCOs are finding that they not only must demonstrate to sophisticated purchasers that their services are cost efficient, they must keep members satisfied. Patients are more educated about health care choices than in the past. They have greater access to information through the Internet and other sources, and they want to be involved in decisions. They want greater choices and greater control for themselves and their families.

An indicator of consumers' desire for more information and control is the recently enacted patient "Bill of Rights." This bill requires information disclosure regarding physician credentials and hospital track records, establishes direct. access to specialists for patients with serious medical conditions, allows for greater patient participation in treatment decisions, and sets internal and external appeals processes. In the face of greater patient empowerment, MCOs must walk a fine line between giving patients what they want and managing costs.

\section{PHARMACY FOCUSES ON OUTCOMES}

The focus on measuring outcomes is reverberating throughout most sectors of health care. Pharmaceutical manufacturers have stepped up their focus on conducting outcomes studies in direct response to managed care organizations. They also have an interest in demonstrating the economic value of their product over that of a competitor's product or another medical intervention. Many of these evaluations are conducted within the structure of a clinical trial but since the patient population involved is not indicative of a typical managed care population, the results are not readily accepted by managed care.

There is increasing discussion about the role of the Food and Drug Administration (FDA) in evaluating cost-effectiveness studies that by design and execution are not able to meet the rigorous standards established for clinical trials. There is concern that this recent move by the FDA to regulate cost-effectiveness claims may add to the difficulty of conducting useful cost-effectiveness studies and applying them to decision making within the market place. Luce, et al., ${ }^{4}$ argue that assertions of cost effectiveness may subvert claims of efficacy and effectiveness and that appropriate disclaimers should be employed, thereby allowing decision makers to reach their own financial conclusions. Many believe that the two issues should remain separate.

The importance of pharmacoeconomic and outcomes research is reflected in the inception and rapid growth of the International Society for Pharmacoeconomics and Outcomes Research, formerly the Association of Pharmacoeconomic and Outcomes Research. This association is an international organization established to promote the practice and science of pharmacoeconomics and outcomes research for the betterment of public health. It facilitates communication among research, regulatory, and academic groups; serves as a resource to shape public policy; and provides a forum for information exchange in this area of knowledge, among other objectives. In 1996, William McGhan ${ }^{5}$ predicted that in 10 years pharmacoeconomics and outcomes research will:
$\boldsymbol{\Delta}$ have international and generalizable rigor;

$\boldsymbol{\Delta}$ be used in interdisciplinary and international dialogue to understand other cultural and economic perspectives;

$\boldsymbol{\Delta}$ be used to improve public health and advance quality of life; and

$\boldsymbol{\Delta}$ help the medical practitioner and researcher incorporate individual patient perspectives into therapy decisions.

\section{THE DATA ISSUES}

Implementing the shift toward managing total patient care on the basis of pharmacoeconomic and outcomes studies requires that the data be available, accurate, and properly utilized. This raises many issues regarding health care data. Who owns it? Who can use it? Who has access to it? Is it valid? Is it current? What can be derived from it?

Employer group coalitions are calling for better standardization of policies and procedures among the health plans with which they contract in an effort to ease confusion for employees and streamline employer processes. For example, they want standardized eligibility transmission file requirements and patient identification cards. They want to establish a registry for immunization that facilitates information retention and sharing when members change health plans. They are interested in physicians having access to electronic patient records on a more timely basis, regardless of the plan relationship, in order to facilitate care and identify trends which might require adjustments.

An example of this type of cooperation is the RxPAD project initiated by the National Independent Practice Association Coalition (NIPAC) in late 1997. NIPAC held focus groups following an employer group summit meeting to evaluate the best method for building a pharmacy data warehouse (or similar consolidation) that would allow for fair use of data, supreme protections for patient confidentiality, and maintenance 
of proprietary issues where they might exist. A key objective of this project is to provide timely and consistently formatted data to the medical groups that are its members. The health plans involved, as well as the physician groups who are NIPAC members, agreed that they should be competing on the basis of quality-of-care issues and not manipulation-of-data issues. This is an effort to fulfill a common . need by leveraging resources and encouraging cooperation of competi-. tors to the benefit of all.

The objectives of the RxPAD project are to:

A establish the data standards;

$\Delta$ obtain data from the various health plans;

A pass the information to the medical groups;

$\Delta$ use the data within the groups to manage clinical activity and risk; and

$\Delta$ pursue research with the data using an Investigational Review Boardbased process of project review, then return the value of the outcomes evaluations to all participants while assuring confidentiality.

This type of collaboration should be fostered and partnerships cultivated to support managed care outcomes studies that can be used to promote healthy population initiatives. Pharmaceutical manufacturers' representatives are part of the NIPAC project at this time, although this involvement is being questioned - an example of a past paradigm that needs to evolve.

\section{APPLICATIONS FOR MANAGED CARE PHARMACISTS}

For the managed care pharmacist, outcomes data have many applications, such as measuring the effectiveness of clinical practice guidelines and making formulary decisions.

\section{Practice Guidelines}

One area of pharmacy data increasingly being used is the evaluation of outcomes of practice guidelines: More and more managed care organizations are using practice guidelines to assist physicians with decision making. These practice guidelines can be the first step toward performing outcomes evaluations. For example, once a practice guideline is implemented and a course of treatment prescribed, pharmacists can evaluate and monitor the outcomes These data can be used to support the contention that guidelines work when used as part of an integrated approach to patient care. As guidelines become more solidly grounded in strong scientific evidence, they become more accepted. Continued demonstration of their value and applicability to varied settings, especially managed care, is needed. Guideline-related outcome information is critical to providing physicians the confidence they require to adopt a practice pattern appropriate for their care site and unique population.

\section{Formulary Decision Making}

Pharmacists also will benefit from the ability to use outcome data for making formulary decisions using decision analysis and conducting cost-effectiveness analyses to improve clinical and policy decision making. ${ }^{6}$ Because pharmacy data has been stored in computer systems since the 1970s, pharmacists have command over valuable data for performing cost-effectiveness and outcomes studies.

Pharmacists in managed care can apply pharmacoeconomic and outcomes results as a defensive strategy to support formulary decisions and quell related discord. If they can show comparable outcomes for a population and assert that decisions are being made based on good practice processes rather than being driven by rebates or other compelling price issues, then decisions will be met with greater acceptance.

\section{Changing Relationships}

Use of pharmacoeconomics and outcomes also has the effect of changing the relationship between the $\mathrm{MCO}$ and its network pharmacists. The pharmacist has the opportunity to play an integral role in making the outcomes process a success by recognizing cost drivers, recognizing opportunities to improve outcomes, and increasing quality-measures performance

Pharmacists also can choose to participate in Phase III economic arms of clinical trials with pharmaceutical manufacturers to gain economic data before products are released, supporting better formulary decisions.

\section{Influence of Ambulatory Pharmacist Care}

A particularly important advantage for pharmacists will be the ability to turn the focus away from component management by demonstrating how ambulatory pharmacy care can affect nonpharmacy costs, no matter where the risk lies. To make total health management programs work effectively, there must be a continuum of care that encompasses every aspect of the patient's contact with the system. If a patient gets through the entire health system and then does not know how to take his or her medication correctly, all the processes that preceded filling the prescription are potentially wasted. In other words, the outcome does not end with the physician's completion of the treatment protocol; it must extend to the pharmacist providing the interaction at the point of service.

A good example of this is what is happening with ambulatory management of HIV/AIDS. AIDS drug treatments have been released for marketing under the FDA fast-track processes. In many cases, due to public demand, the need for flexibility in product selection, and the political sensitivity of the diagnosis itself, this group of drugs has been left untouched by typical formulary processes despite their high costs. Instead, there have been retrospective reviews of the drug class expenditures and the numbers are impressive. A comprehensive look at all categories of care within AIDS, however, may reveal fewer inpatient days, a lower rate of opportunistic infections and hospitalizations 
- Continued from page 263

due to those infections, and fewer home health care expenditures in patient groups that are being aggressively managed. AIDS patients who are effectively treated with the newest drug regimens can potentially work longer, a benefit to both the patient and his or her employer.

A critical component for the managed care AIDS patient is the retail pharmacist. Complicated drug regimens with significant interaction possibilities and side effect profiles, as well as the sheer volume of agents used to treat the illness, require a compassionate and well-informed pharmacist and a time-consuming consultation at the point of service. Compliance is critical for success and recognizing the value of pharmacist care in the network pharmacy is paramount.

The AIDS-patient category is a timely example that demonstrates the positive humanistic outcome of ambulatory drug therapies and adherence to clinical guidelines. The challenge is to show clinical improvement and acquire actual costs which may not be tracked at the plan itself. Although more money is being spent on AIDS drugs in an ambulatory setting, there are definite measures of success to justify these expenditures.

Pharmacists are in a unique position to demonstrate how the use of treatment guidelines in ambulatory drugs for AIDS patients can defray or eliminate charges incurred for other health care events.

\section{CHALLENGES AND OPPORTUNITIES}

The managed care pharmacist will need to find partners with credibility, competence, and resources to conduct outcomes evaluations that benefit the health care industry overall. These will include academic institutions, government organizations, and pharmaceutical manufacturers, or combinations of these.

The Agency for Health Care Policy and Research is conducting a five-year evidence-based practice program for which sites are being chosen to conduct outcomes studies. These studies not only provide a resource for MCOs to obtain outcomes information but also offer the opportunity to participate in and develop partnerships with other medical and research organizations to collaborate on assigned areas. It is a prime opportunity for managed care pharmacists to get involved.

Pharmaceutical manufacturers are increasingly faced with the paradox of trying to meet the needs of demanding MCOs looking for cost-effectiveness outcomes data as part of formulary processes, yet are unwilling or ill-equipped to participate in such research.

Pharmaceutical manufacturers are attempting to meet increased demand for pharmacoeconomic studies but they need more collaborative partners to design valid, objective evaluations. At issue, perhaps, is the past credibility of pharmaceutical manufacturer forces. To address this concern, increasing numbers of firms are developing their medical affairs departments to include field personnel with backgrounds and training in pharmacoeconomic research to support customer needs and complete outcomes studies.

As initiatives are launched and outcomes studies grow in importance, some additional challenges arise. How will the results of outcomes studies drive corporate decisions? When are quality of life and value of outcomes going to eclipse premium costs as the driver for health management organizations?

\section{CONCLUSION}

Consumers of health care, both patients and buyers, will continue to demand more value. They want proof that their costs result in better health status and more efficient care. Outcomes evaluations are part of this proof of value. Outcomes should drive decisions in MCOs and the successful presentation of results will justify future premium increases because of documented value being achieved.

As long as resources are limited and imperatives to reduce unnecessary costs due to inappropriate utilization continue to be a daily issue, ${ }^{7}$ pharmacoeconomic and outcomes study results can help support decisions facing managed health care. These types of evaluations lend rational perspective and in many cases supply the defense needed to justify a decision that may be met with opposition by the population served.

While pharmacists in MCOs must defend the escalating budgets they manage, at the same time the maturation of the marketplace has driven the role of pharmacy benefits managers from simple administration of the benefit to sharing patient care responsibility.

The daily activity of the managed care pharmacist should incorporate questions about why and how decisions are made and whether an outcome evaluation or pharmacoeconomic study can and should be applied to the decision to support its enactment.

Knowledge of the techniques is still limited, but there is a significant movement toward improving this, and many resources are available to gain competence. The profession must evolve as heath care evolves. As long as the managed pharmacy industry is unable to deliver cost savings while maintaining quality of life and satisfaction measures with good clinical outcomes, attacks will continue. Well-executed pharmacoeconomic and outcomes evaluations delivered to the public health community are ways to answer those attacks.

The pharmaceutical manufacturers, government agencies, and academic centers that have developed expertise in conducting these kinds of research are logical partners to facilitate such studies. Organizations that align themselves in strategic partnerships to move forward will be the ultimate winners.

This is a call to action. Determine needs, look for partners, and get involved in outcomes research. The dividends will be large, and pharmacists are clearly among the most qualified professionals to accomplish these agendas.

References

1. Freudenheim M. Not quite what doctor ordered: drug substitutions add to discord over managed care. New York Times 1996(Oct); Section D: 1 
2. Schulman KA, Rubenstein LE, Abernethy DR, Seils DM, Sulmasy DP. The effect of pharmaceutical benefits managers: is it being evaluated? Ann Intern Med 1996; 124: 906-13.

3. Winslow R. Firm hands: corporate coalitions have been a major force in keeping costs down. What's their game? The Wall Street Journal 1997(Oct): R19.

4. Luce BR, Hillman AL. When is a cost-effectiveness claim valid? How much should the FDA care? Am J Man Care 1997; 3: 1660-66.

5. McGhan W. Pharmacoeconomics and outcomes research-visions for the 21 st century. Clinical Therapeutics 1996; 18(Suppl A): 1-5.

6. Mullins CD, Cooke CE, Cooke JL. Applications of pharmacoeconomics for managed care pharmacy. J Managed Care Pharm 1997; 3: 720-26. 7. Kobelt G. Health economics: an introduction 10 economic evaluation. London, England: Office of Health Economics, 1996.

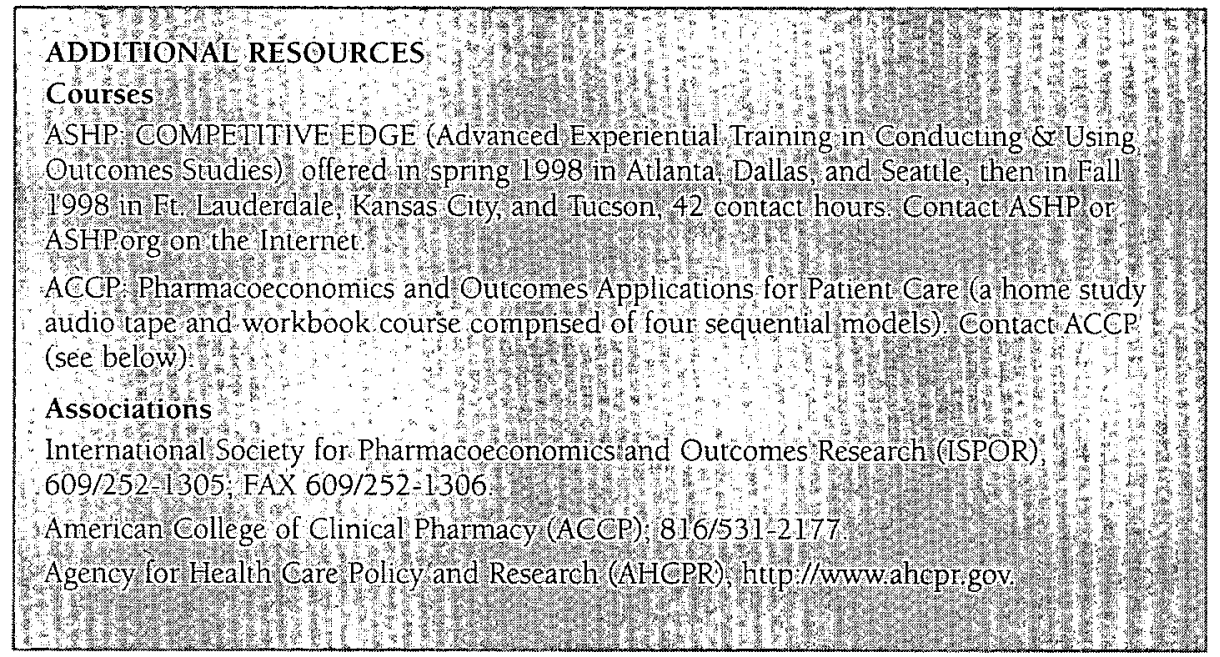





For medical information: 800-506-4959.



๑) 1998 ALZA Corporation 